\title{
Què vol dir
dissolució tampó?
}

\author{
Montserrat Tortosa Moreno \\ IES Ferran Casablancas (Sabadell) \\ mtortosa@xtec.net
}

El pH de l'aigua d'un aquari té un valor que s'ha de mantenir constant. És fàcil imaginar-se què passaria en cas contrari. El mateix podem dir del plasma sanguini, de la suor, de l'orina, dels xampús, d'una loció infantil i d'un gran reguitzell de líquids. Un pH constant s'aconsegueix amb una dissolució tampó o reguladora del $\mathrm{pH}$. Però a la pràctica, què significa que manté el $\mathrm{pH}$ constant?

\section{OBJ ECTIUS}

- Preparar una solució tampó i mesurar l'evolució del $\mathrm{pH}$ en afegir petites quantitats d'àcid o de base.

- Determinar si diversos líquids d'us comú són reguladors del $\mathrm{pH}$, i interpretar-ho teòricament.

- Comparar el comportament de líquids reguladors i no reguladors del $\mathrm{pH}$.

\section{INTRODUCCIÓ}

El pH és una magnitud que mesura el grau d'acidesa o basicitat. En el cas de dissolucions aquoses $\mathrm{pH}=-\log \left[\mathrm{H}_{3} \mathrm{O}^{+}\right]$

$\mathrm{El} \mathrm{pH}$ varia lleugerament amb la temperatura, a 25 ${ }^{\circ} \mathrm{C}$ una solució de $\mathrm{pH}=7$ és neutra, una solució àcida té un $\mathrm{pH}<7$ i una solució bàsica té un $\mathrm{pH}>7$.

L'aigua desionitzada és neutra, té un $\mathrm{pH}=7$, tanmateix aquest valor pot variar en diverses unitats en afegir-hi una petita quantitat, una gota, d'àcid o de base.

Una gran quantitat de processos químics i bioquímics ocorren a un $\mathrm{pH}$ concret i pràcticament constant, que no varia encara que s'incorporin noves substàncies al procés. Aquest comportament s'aconsegueix amb un sistema regulador de $\mathrm{pH}$ o sistema tampó.

Una dissolució reguladora està constituïda per un àcid feble i una sal d'aquest àcid i de base forta, en concentracions similars (per exemple una solució que sigui àcid acètic $0,1 \mathrm{M}$ al mateix temps acetat de sodi $0,1 \mathrm{M})$; o bé per una base feble i una sal d'aquesta base i d'àcid fort, en concentracions similars (per exemple amoníac 0,20 M i nitrat d'amoni 0,15 M). La reacció d'equilibri de l'àcid o la base febles explica que el $\mathrm{pH}$ es mantingui pràcticament constant encara que s'hi afegeixin petites quantitats d'un àcid o una base.

\section{MATERIAL I EQUIPAMENT}

\section{Material de laboratori}

- 2 Vasos de precipitats de $100 \mathrm{ml}$

- Suport, 2 pinces, 2 nous

- 2 Varetes de vidre

- Proveta de $100 \mathrm{ml}$

- Pipetes Pasteur de $2 \mathrm{ml}$ o goters graduats

- Ulleres de seguretat

\section{Productes}

- $\mathrm{CH}_{3} \mathrm{COOH} 0,1 \mathrm{M}$

- $\mathrm{NaOH} 0,1 \mathrm{M}$

- $\mathrm{HCl} 0,01 \mathrm{M}$

- $\mathrm{NaOH} 0,01 \mathrm{M}$

- Aigua desionitzada

- Aigua amb gas

- Sucs de fruita

- begudes diverses

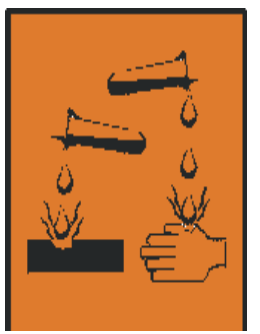




\section{Elements de l'equip Multilog}

- 2 Sensors de $\mathrm{pH}$ (rang 0 a 14 , resolució 0,02 , temps de resposta 10 segons) amb els corresponents elèctrodes

- Interfície Multilog Pro amb cable USB

- Ordinador

\section{PROCEDIMENT}

\section{Muntatge de l'experiència}

1) Preparació de la solució tampó:

- Aboquem $50 \mathrm{ml}$ d'àcid acètic $0,1 \mathrm{M}$ en el vas de precipitats.

- Mesurem $25 \mathrm{ml}$ de $\mathrm{NaOH} 0,1 \mathrm{M}$ i els aboquem en el mateix vas.

- Posem $75 \mathrm{ml}$ d'aigua desionitzada en un altre vas.

- Preparem les pipetes Pasteur (fig. 1) per fer a cada vas 3 addicions successives d'un $\mathrm{ml}$ d' $\mathrm{HCl}$ $0,01 \mathrm{M}$ i 3 addicions d'un $\mathrm{ml}$ d'NaOH 0,01M.

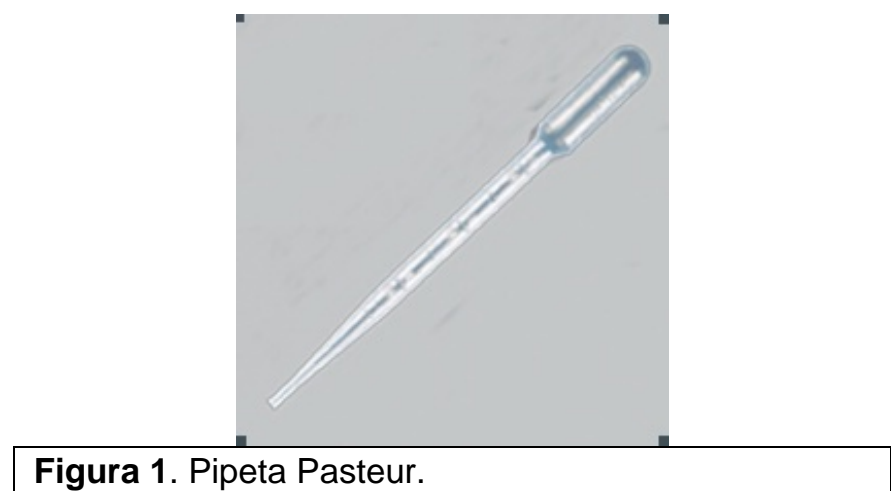

L'àcid acètic i l'hidròxid de sodi reaccionen per donar acetat de sodi i aigua. En afegir un nombre de mols d'hidròxid de sodi inferior als d'àcid acètic, a la mescla resultant hi ha tant acetat de sodi que s'ha format com l'àcid acètic sobrant: la mescla constitueix una dissolució tampó.

2) Es connecten els dos sensors de $\mathrm{pH}$ a les entrades IO-1 (altra dissolució) i IO-2 (aigua desionitzada) de la interfície (fig.2).

3) Es connecta la interfície a l'ordinador mitjançant el cable USB o el connector de nou pins.

4) S'engega primer la interfície i després s'obre el programa Multilab

\section{Configuració del sistema}

Cal configurar el sistema perquè enregistri les dades de $\mathrm{pH}$ en funció del temps:

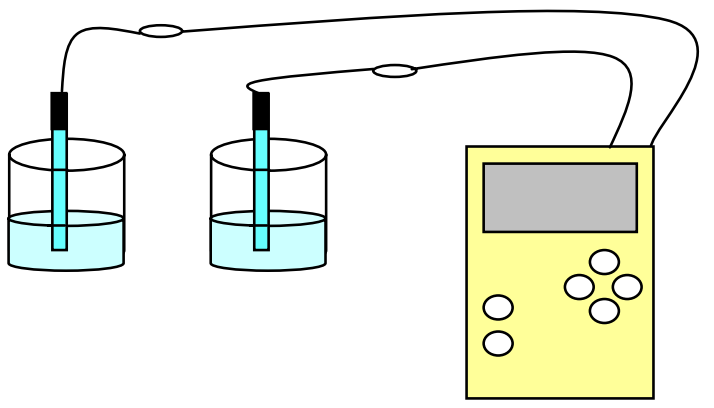

Figura 2. Diagrama del muntatge per a l'estudi de la capacitat reguladora una solució tampó.

- Clicant el botó configurar ajudant, s'obren tres pantalles consecutives (fig 3 a 6 ).

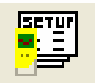

Figura 3. Botó configurar ajudant.

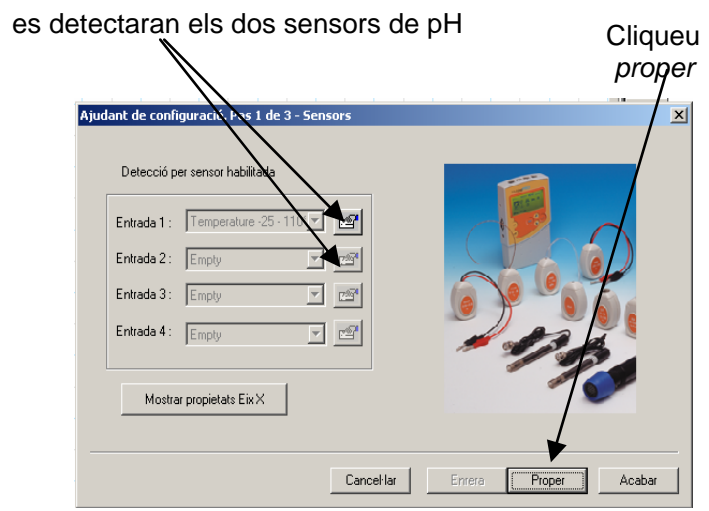

Figura 4. Primera pantalla de l'ajudant de configuració.

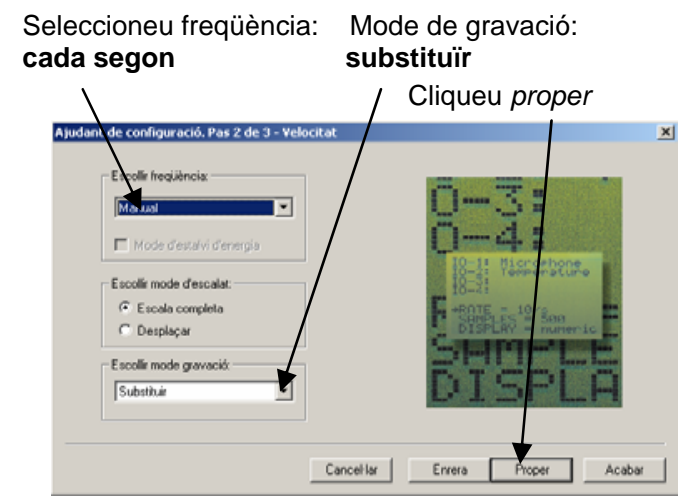

Figura 5. Segona pantalla de l'ajudant. 


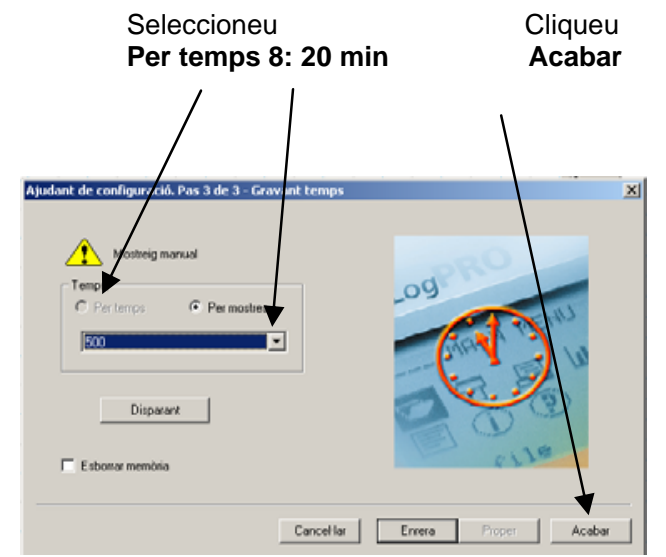

Figura 6. Darrera pantalla de configuració.

\section{Execució de l'experiència}

Durant tota l'experiència cal tenir present que el temps de resposta dels sensors de pH és d'uns 10 segons.

- Poseu en marxa l'adquisició de les dades amb el botó executar (fig. 7) observeu els valors de pH de cada solució.

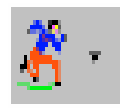

\section{Figura 7. Botó Executar.}

- Amb la pipeta Pasteur agafeu $2 \mathrm{ml}$ d' $\mathrm{HCl}$ 0,01 M i afegiu-ne $1 \mathrm{ml}$ a la solució d'aigua desionitzada i 1 $\mathrm{ml}$ a la dissolució tampó, agiteu cada solució amb una vareta de vidre (ALERTA, cal que sempre utilitzeu la mateixa vareta per a cada solució) espereu 10 segons que s'estabilitzi el pH

- Repetiu el pas anterior dues vegades més

- Amb la pipeta Pasteur agafeu $2 \mathrm{ml}$ de $\mathrm{NaOH} 0,01$ $\mathrm{M}$ i afegiu-ne $1 \mathrm{ml}$ a la solució d'aigua desionitzada i $1 \mathrm{ml}$ a la dissolució tampó, agiteu i espereu 10 segons que s'estabilitzi el $\mathrm{pH}$

- Repetiu el pas anterior dues vegades més

- Finalitzeu la captació de dades amb el botó stop (fig. 8).

Figura 8. Botó Stop.

Nota: És convenient afegir una quantitat d'àcid o de base prou gran perquè pugui fer variar el $\mathrm{pH}$ de manera apreciable si s'afegeix a un líquid no tampó com poden ser un àcid o base febles. Per això es considera adequat fer les addicions de $\mathrm{ml}$ en $\mathrm{ml}$ (i no gota a gota) per a concentracions d' $\mathrm{HCl}$ i de $\mathrm{NaOH}$ $0,01 \mathrm{M}$.

És interessant repetir l'experiència utilitzant aigua amb gas, sucs de fruita naturals o comercials $\mathrm{i}$ begudes diverses.

\section{RESULTATS ESPERATS}

\section{a) Aigua desionitzada i solució tam- pó preparada}

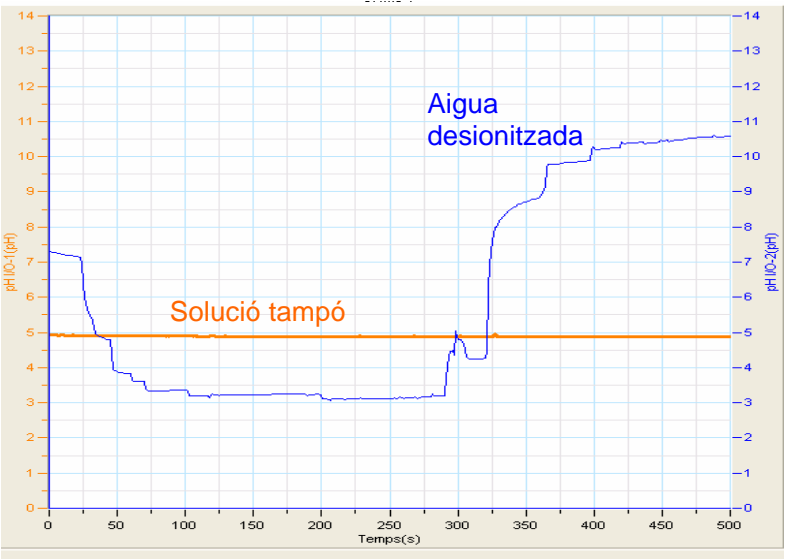

Figura 9. Evolució del pH obtinguda en fer 3 addicions successives d' $1 \mathrm{ml}$ de $\mathrm{HCl} 0,01 \mathrm{M}$ seguides de 3 addicions de $\mathrm{NaOH} 0,01 \mathrm{M}$ a $75 \mathrm{ml}$ d'aigua desionitzada (línia blava) i $75 \mathrm{ml}$ de solució tampó (línia carbassa). Les addicions han estat fetes amb una pipeta Pasteur.

\section{b) Aigua desionitzada i aigua amb gas}

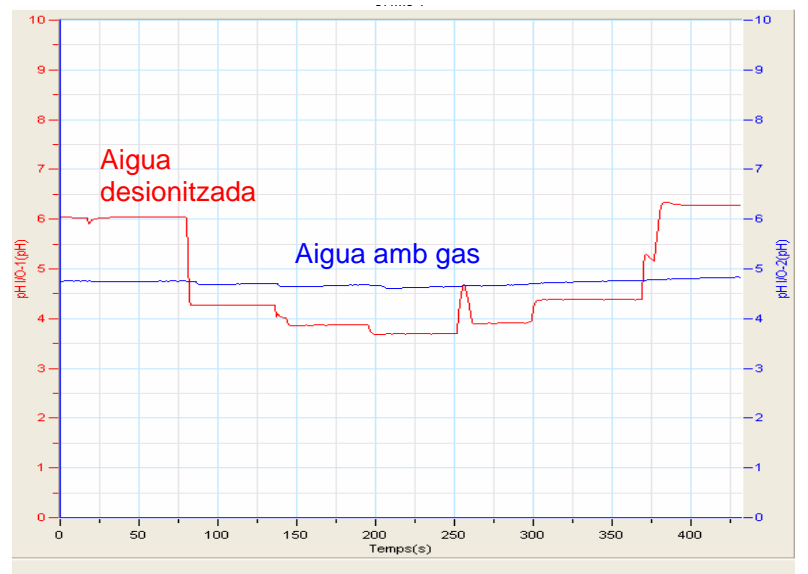

Figura 10. Evolució del pH obtinguda en fer 3 addicions successives d' $1 \mathrm{ml}$ de $\mathrm{HCl} 0,01 \mathrm{M}$ seguides de 3 addicions de $1 \mathrm{ml}$ de $\mathrm{NaOH} 0,01 \mathrm{M}$ a $50 \mathrm{ml}$ d'aigua desionitzada (línia vermella) i $50 \mathrm{ml}$ d’aigua amb gas (línia blava). 


\section{c) Aigua i sucs de fruita}
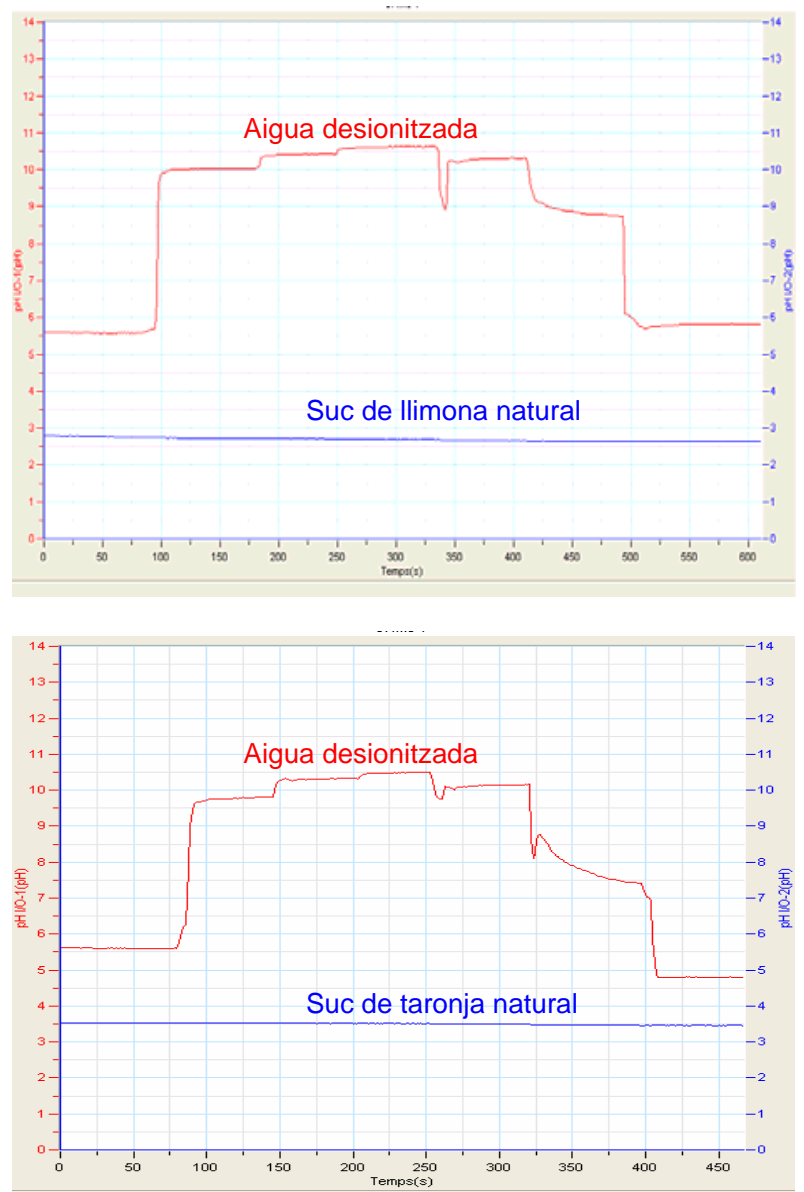

Figura 11. Evolució del pH obtinguda en fer 3 addicions successives d'1 $\mathrm{ml}$ de $\mathrm{NaOH} 0,01 \mathrm{M}$ seguides de 3 addicions de $\mathrm{HCl} 0,01 \mathrm{M}$ a $50 \mathrm{ml}$ d'aigua desionitzada(línies vermelles) i $50 \mathrm{ml}$ de suc de llimona i de taronja naturals, acabats d'esprémer (línies blaves).

\section{COMENTARI DELS RESULTATS}

En una solució reguladora es produeix l'equilibri químic de l'àcid feble. Pel cas general d'un àcid de fórmula HA és

$$
\mathrm{HA}+\mathrm{H}_{2} \mathrm{O} \leftrightarrows \mathrm{A}^{-}+\mathrm{H}_{3} \mathrm{O}^{+}
$$

L'expressió de la seva constant d'acidesa $\mathrm{K}_{\mathrm{a}}$ és

$$
\mathrm{K}_{\mathrm{a}}=\left[\mathrm{A}^{-}\right]\left[\mathrm{H}_{3} \mathrm{O}^{+}\right] /[\mathrm{HA}]
$$

Si l'àcid està sol, la concentració d'àcid no dissociat HA és molt més gran que la de l'anió $A^{-}$. En canvi si a la solució hi ha la sal $\mathrm{NaA}$, aquesta donarà lloc als ions $\mathrm{Na}^{+}$i $A^{-} \mathrm{i}$, per tant, les concentracions d'HA i de $A^{-}$poden arribar a ser del mateix ordre.
Com s'explica el comportament del pH d'una solució que conté un àcid feble i la seva sal sòdica en afegir-hi àcid?

Si hi afegim àcid, aportem ions hidroni a l'equilibri i aquest es desplaça cap als reactius segons el principi de Le Chatelier. El valor de les concentracions ve regit per la constant d'acidesa $\mathrm{K}_{\mathrm{a}}$.

En el cas d'una solució tampó les concentracions d'HA i $A^{-}$són grans en relació a la constant d'acidesa. Per això la concentració d'ions hidroni, i en conseqüència el $\mathrm{pH}$, variarà poc.

$$
\mathrm{HA}+\mathrm{H}_{2} \mathrm{O} \leftrightarrows \mathrm{A}^{-}+\mathrm{H}_{3} \mathrm{O}^{+}
$$

Com s'explica el comportament en afegir petites quantitats d'hidròxid?

Si afegim hidròxid, aportem ions hidròxid a l'equilibri. Aquests ions reaccionen amb el ions hidroni per formar aigua:

$$
\mathrm{OH}^{-}+\mathrm{H}_{3} \mathrm{O}^{+} \leftrightarrows 2 \mathrm{H}_{2} \mathrm{O}
$$

En treure els ions hidroni de la reacció

$$
\mathrm{HA}+\mathrm{H}_{2} \mathrm{O} \leftrightarrows \mathrm{A}^{-}+\mathrm{H}_{3} \mathrm{O}^{+}
$$

l'equilibri es desplaçarà cap als productes, segons el principi de Le Chatelier.

En el cas d'una solució tampó les concentracions d'HA i $A^{-}$són grans en relació a la constant d'acidesa, i per tant el pH variarà poc

$$
\mathrm{HA}+\mathrm{H}_{2} \mathrm{O} \leftrightarrows \mathrm{A}^{-}+\mathrm{H}_{3} \mathrm{O}^{+}
$$

A la figura 10 pot veure's que el $\mathrm{pH}$ de l'aigua amb gas no varia en afegir l'àcid o la base. Per tant, es tracta d'una solució tampó.

Per ser una solució tampó cal que hi hagi un àcid feble i una de les sals d'aquest àcid i base forta. En aquest cas, el gas és diòxid de carboni, que en dissoldre's a l'aigua forma àcid carbònic, que és un àcid feble:

$$
\mathrm{CO}_{2}+\mathrm{H}_{2} \mathrm{O} \leftrightarrows \mathrm{H}_{2} \mathrm{CO}_{3}
$$

Es tracta d'un àcid dipròtic :

$$
\begin{gathered}
\mathrm{H}_{2} \mathrm{CO}_{3}+\mathrm{H}_{2} \mathrm{O} \leftrightarrows \mathrm{HCO}_{3}{ }^{-}+\mathrm{H}_{3} \mathrm{O}^{+} \\
\mathrm{HCO}_{3}{ }^{-}+\mathrm{H}_{2} \mathrm{O} \leftrightarrows \mathrm{CO}_{3}{ }^{2-}+\mathrm{H}_{3} \mathrm{O}^{+}
\end{gathered}
$$

A l'aigua amb gas hi ha cations metàl-lics, com el $\mathrm{Na}^{+} \mathrm{O}$ el $\mathrm{Ca}^{2+}$, que amb els ions bicarbonat $i$ carbonat formen la sal corresponent, que queda dissolta.

Els sucs de fruita contenen àcids febles i també cations metàl-lics; és a dir que tenen la composició de solucions tampó. 
Cas general:

$$
\mathrm{HA}+\mathrm{H}_{2} \mathrm{O} \leftrightarrows \mathrm{A}^{-}+\mathrm{H}_{3} \mathrm{O}^{+}
$$

l'anió $A^{-}$forma la sal de base feble amb els ions de sodi, potassi o altres que hi ha als sucs de fruita.

Per al suc de taronja, de llimona, i de pinya americana l'àcid majoritari és el cítric, $\mathrm{C}_{6} \mathrm{H}_{8} \mathrm{O}_{7}$, àcid 2hidroxipropantricarboxílic:

\section{$\mathrm{CH}_{2} \mathrm{COOH}-\mathrm{C}(\mathrm{OH}) \mathrm{COOH}-\mathrm{CH}_{2} \mathrm{COOH}$}

Aquest àcid també és utilitzat com a conservant en molts sucs de fruites envasats.

Aquest treball forma part d'un projecte elaborat durant una llicència retribuïda concedida pel Departament d'Educació el curs 2004-05 (Resolució 16 juliol 2004. DOGC núm 4182 de 26-07-2004). 